\title{
A validated HPLC method for simultaneous estimation of Melatonin and Octyl Methoxycinnamate in combined pharmaceutical applications
}

\author{
Gülçin ARSLAN AZIZZOĞLU, Erkan AZIZZOĞLU, Sakine TUNCAY TANRIVERDİ, Özgen ÖZER
}

\begin{abstract}
A simple, fast and precise reverse phase high performance liquid chromatographic method has been developed for the simultaneous determination of Melatonin and Octyl Methoxycinnamate. Melatonin has become an attractive substrate in sunscreen formulations because of its high antioxidant and photo-protection properties. Octyl methoxycinnamate is one of the chemical UV filter that can be found most of the sunscreen formulations up to $7.5 \%$ according Food and Drug Administration. The aim of the present study was to develop and validate a High-Performance Liquid Chromatography method for the determination of Melatonin and Octyl Methoxycinnamate in combined pharmaceutical or cosmetic applications. As a model of combined pharmaceutical applications, a microemulsion consisting of Melatonin and Octyl Methoxycinnamate was also prepared and characterized in terms of droplet size, $\mathrm{pH}$ and viscosity. The separation was
\end{abstract}

Gulçin Arslan Azizoğlu, Erkan Azizoğlu, Sakine Tuncay Tanrıverdi, Özgen Özer

Department of Pharmaceutical Technology, Faculty of Pharmacy, Ege University, Izmir, Turkey

Corresponding Author:

Sakine Tuncay Tanriverdi

e-mail: sakinetuncay@windowslive.com

Submitted / Gönderilme: 13.01.2017 Revised / Düzeltme: 20.06.2017 Accepted / Kabul: $\quad 20.06 .2017$

How to cite this article: Arslan Azizoğlu G, Azizoğlu E, Tuncay Tanrıverdi S, Özer Ö. A validated HPLC method for simultaneous estimation of melatonin and octyl methoxycinnamate in combined pharmaceutical applications. Marmara Pharm J 2017; 21 (4): 921-930 performed with a Waters XTerra RP C18 (5 $\mu \mathrm{m}, 4.6$ x $150 \mathrm{~mm})$. All HPLC assays were performed with $10 \mu$ injection volume, mobile phase consisting of acetonitrile and water, using gradient elution starting at $20 \%$ and ending at $90 \%$ of acetonitrile with a flow rate of $1.5 \mathrm{ml} \mathrm{min}^{-1}$. The eluent was monitored with UV detection at $222 \mathrm{~nm}$ for Melatonin and $306 \mathrm{~nm}$ for Octyl Methoxycinnamate. The method was validated according to ICH guidelines. Validation parameters were specificity, accuracy, precision (repeatability and reproducibility), linearity, limit of detection (LOD) and limit of quantification (LOQ). Analytical method development results indicated that the LOD values were 0.132 and $0.049 \mu \mathrm{g} / \mathrm{ml}$; LOQ values were 0.4 and $0.15 \mu \mathrm{g} / \mathrm{ml}$ and assay exhibited a linear range of $0.5-60 \mu \mathrm{g} / \mathrm{ml}$ for Melatonin and Octyl Methoxycinnamate, respectively.

Key words : Melatonin (PubChem CID: 896); Octyl methoxycinnamate (PubChem CID: 5355130) ; RP-HPLC method development.

\section{Introduction}

Melatonin (MEL) is a well-known neuroendocrine mediator produced by the pineal gland that was discovered in $1960 \mathrm{~s}$ [1]. Melatonin is involved in numerous biological functions including circadian rhythm, sleep, the stress response, aging, and immunity. Beside those, melatonin is also synthesized in skin activated by a local melatoninergic system in protection against ultraviolet radiation (UVR) induced damages. Therefore, combination of endogenous and topically applied exogenous melatonin makes this molecule attractive as a potent antioxidant for sunscreen formulations [2-4].

Sunscreen formulations are composed of different chemicals and UV filters are the most essential ingredients among them. Octyl methoxycinnamate (OMC) is a widely used UV-B filter which absorbs radiation in the $290-320 \mathrm{~nm}$ region of the UV spectrum. According to Food and Drug Administration (FDA) regulations, sunscreen products can contain OMC up to $7.5 \%$ [5].

There are different factors affecting the consumers' choice about the sunscreen products. In recent years, transparent 
dispersions have been used as popular sunscreens. Microemulsions are thermodynamically stable colloidal systems consisting of oil and water phases which are stabilized by surfactants and co-surfactants [6]. Their use as topical delivery systems derives from their multiple advantages compared to other dermatological formulations, such as ease of preparation, thermodynamic stability and penetration-enhancing properties [7]. Microemulsions are optically isotropic, transparent or slightly opalescent drug delivery systems with low viscosity. These features ensure the production of transparent, nonsticky and easily spreadable formulations [8].

A number of different determination methods have been developed for MEL and OMC individually $[9,10]$. There is no any analytical method that has been reported yet for determination of these drugs together. Therefore, the present research work aims to develop a simple, sensitive, accurate and reproducible method for simultaneous estimation MEL and OMC in combined pharmaceutical applications by a single Reversed Phase High Performance Liquid Chromatography (RP-HPLC) method. A microemulsion formulation consisting of MEL and OMC was used as a combined model system of the two active pharmaceutical ingredient (API). Microemulsion was prepared using pseudoternary phase diagrams and characterized in terms of droplet size, $\mathrm{pH}$ and viscosity.

\section{Materials and Methods}

\subsection{Materials}

Melatonin was purchased from BioShop (Burlington, Ontario, Canada). OMC was a kind gift from Mikrogen
(Istanbul, Turkey). Tween 80 was purchased from Merck Transcutol P was obtained from Gattefossé (Lyon, France). All solvents were HPLC grade and purchased from Merck (Darmstadt, Germany). Highly purified water was obtained through ultrapure water system (Model-Arium 611) of Sartorius AG (Goettingen, Germany).

\subsection{Preparation and Characterization of Microemulsions}

Nine microemulsions which were composed of isopropyl myristate (IPM) (oil phase) and Tween80:Trascutol $\mathrm{P}$ (surfactant:co-surfactant) with different $(\mathrm{w} / \mathrm{w})$ ratios $(1: 9$, $2: 8,3: 7,4: 6,5: 5,6: 4,7: 3,8: 2$, and 9:1) were prepared with a total weight of $5 \mathrm{~g}$ in a glass beaker. Surfactant and cosurfactant ratio was kept 2:1 at all times. Deionized water was added drop wise to these microemulsions with continuous stirring using a magnetic stirrer until the it begins to be slightly turbid and then turns over clear with continuous rotation and total water (aqueous phase) amounts were recorded. Pseudoternary phase diagrams were constructed using Triangle Phase Diagram software. Samples exhibiting a transparent and homogeneous state were assigned to a microemulsion region in the phase diagram. After the microemulsion regions in the phase diagram were identified, typical microemulsion vehicles were selected and prepared with addition of $1 \%$ MEL and $5 \%$ OMC (w/w). Both MEL and OMC have lipophilic characters, so they were dissolved in oil phase. The molecular structures of the APIs are shown in Figure 1.

The average droplet size and polydispersity index of microemulsions were measured at $25 \pm 2{ }^{\circ} \mathrm{C}$ by photon correlation spectroscopy (Nano ZS, Malvern Instruments,

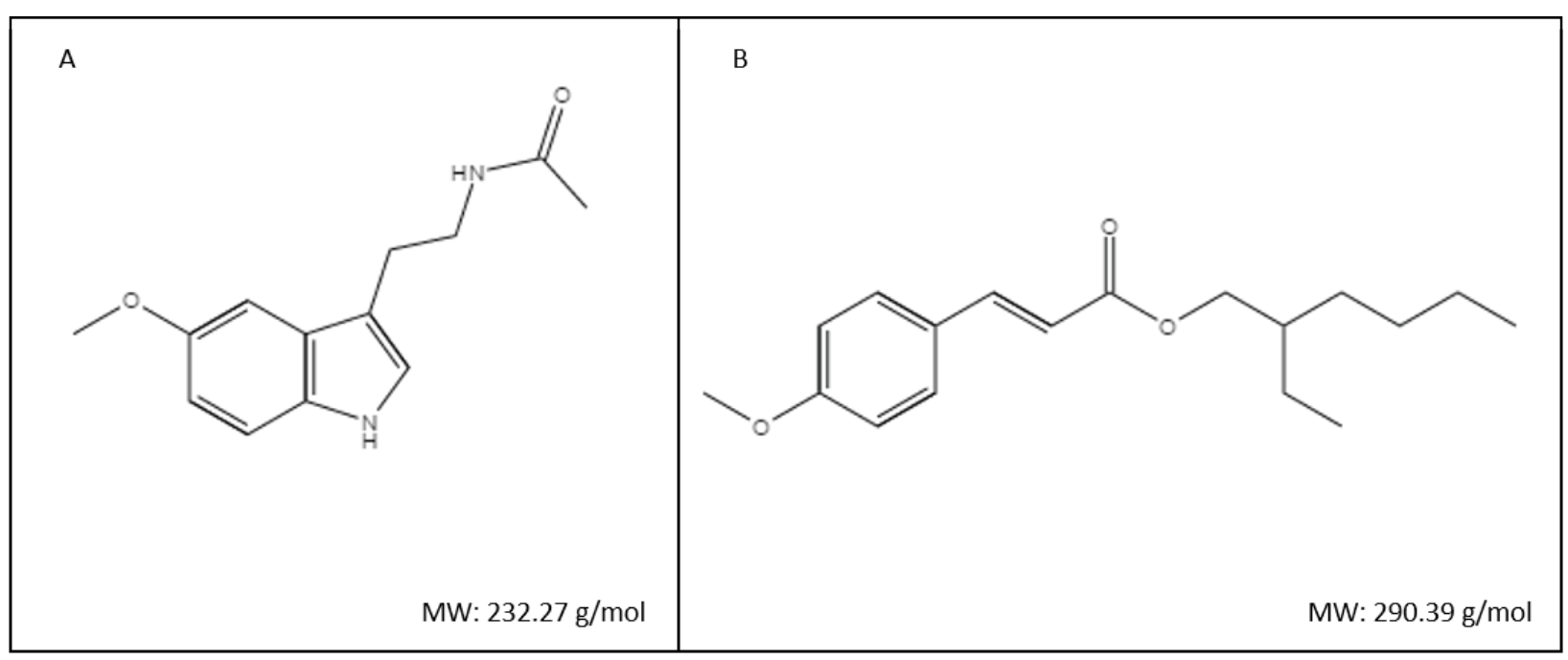

Figure 1. Chemical structures of (A) melatonin and (B) octyl methoxycinnamate. 
$\mathrm{UK})$. The $\mathrm{pH}$ values were detected at $25 \pm 2{ }^{\circ} \mathrm{C}$ using a digital pH-meter (HI 221 - Mauritius). The viscosities of microemulsions were measured at $25 \pm 2{ }^{\circ} \mathrm{C}$ using a viscometer (AND Vibro Viscometer SV10).

\subsection{Instrumentation and Chromatographic Conditions}

An Agilent 1100 HPLC system (Wilmington, DE, USA) equipped with a solvent degasser, quaternary pump, autosampler, column oven and a diode array detector was used in the study. Agilent ChemStation software was used for instrument operation control and data collection. Waters XTerra RP C18 (5 $\mu \mathrm{m}, 4.6$ x $150 \mathrm{~mm}$ ) column was used for separation. All HPLC assays were performed with $10 \mu$ injection volume, mobile phase consisting of acetonitrile and water, using gradient elution starting at 20 $\%$ and ending at $90 \%$ of acetonitrile with a flow rate of 1.5 $\mathrm{ml} \mathrm{min}{ }^{-1}$. The details of gradient elution can be found at Table 1 . The column oven was conditioned at $25^{\circ} \mathrm{C}$ and analysis time was 15 minutes including re-equilibration time. $\lambda \max$ values were determined by scanning with DAD detector between 200-400 $\mathrm{nm}$. Prior to the injection, column was equilibrated until the UV signal and back pressure were stabilized with the mobile phase flowing through the system.

Table 1. Gradient conditions of the proposed HPLC method

\begin{tabular}{ccc}
\hline $\mathrm{T}(\mathbf{m i n})$ & A \% (ACN) & B \% (Water) \\
\hline 6.50 & 20 & 80 \\
\hline 6.51 & 90 & 10 \\
\hline 11.00 & 90 & 10 \\
\hline 11.10 & 20 & 80 \\
\hline
\end{tabular}

\subsection{Analytical Method Validation}

The described method was validated according to ICH guidelines [12] with respect to specificity, accuracy, precision (repeatability and reproducibility), linearity, limit of detection and limit of quantification.

\subsubsection{Preparation of Standard Solutions}

Stock solutions of MEL and OMC were prepared by dissolving $10 \mathrm{mg}$ of each API in PBS:ethanol (1:1) (v/v) mixture in a 10 $\mathrm{ml}$ volumetric flask. Standard calibration solutions of MEL and OMC having concentrations in the range of $0.5-60 \mu \mathrm{g} / \mathrm{ml}$ were prepared by diluting stock solutions with PBS:ethanol $(1: 1)(\mathrm{v} / \mathrm{v})$ mixture.

\subsubsection{Specificity}

Specificity of an analytical method shows the detection ability of the desired component(s) in the presence of other components (i.e. excipients) that may be expected to be present in the sample. In order to determine the specificity of the analytical method, dilution solution, PBS:ethanol $(1: 1)(\mathrm{v} / \mathrm{v})$ and the placebo solution that contains the microemulsion formulation without the APIs were injected into the chromatographic system.

\subsubsection{Accuracy}

The accuracy of the method was determined by recovery studies which help the comparison of the experimental amount and the theoretical amount. The recovery studies were evaluated in triplicate using three concentrations, 40, 50 and $60 \mu \mathrm{g} / \mathrm{ml}$.

\subsubsection{Precision}

The precision of method was verified by obtaining repeatability, intermediate precision and reproducibility parameters. Repeatability was checked by injecting six individual sample preparations of MEL and OMC at $50 \mu \mathrm{g} /$ $\mathrm{ml}$ concentration. In order to determine the intermediate precision, six individual samples at a concentration of $50 \mu \mathrm{g} / \mathrm{ml}$ was prepared and analyzed by two analysts. Reproducibility of the system was determined by preparation of six different samples from the same stock solution at the same concentration of $50 \mu \mathrm{g} / \mathrm{ml}$. Standard deviation (SD) and relative standard deviation (RSD) of the area for each API were calculated and evaluated.

\subsubsection{Linearity}

The linearity between peak area and concentration was analyzed using calibration curve obtained from six standard solutions of MEL and OMC at 60, 40, 20, 10, 5 and $1 \mu \mathrm{g} /$ $\mathrm{ml}$ concentrations in triplicate. The calibration curves were plotted with the responses of peak area versus concentration of analyte and fitted using least squares linear regression.

\subsubsection{Limit of Detection (LOD) and Limit of Quantification (LOQ)}

The LOD and LOQ value determinations were based on the standard deviation of the response and the slope. Following equations (1) and (2), where $\sigma$ is the standard deviation of 
the response and $\mathrm{S}$ is the slope of the calibration curve, were used to calculate the LOD and LOQ based on the calibration curve.

$\mathrm{LOD}=3.3 \sigma / \mathrm{S}$

$\mathrm{LOQ}=10 \sigma / \mathrm{S}$

\subsection{Ex-vivo Permeation Study of the MEL-OMC Microemulsion Formulation}

Ex-vivo permeation studies were performed on Wistaralbino rat's abdominal skin samples mounted on vertical glass Franz-type diffusion cells with an effective diffusion area of $0.384 \mathrm{~cm}^{2}$. The skin samples were excised immediately after the sacrificing the animas used for another study, and were purified from the surrounding tissue and hair on top. In the receptor phase, PBS:Ethanol (1:1) pH 7.4 was used as the medium and constantly stirred with a magnetic stirrer at $600 \mathrm{rpm}$. The sink conditions were taken into consideration during the experiment. The system was kept at $37^{\circ} \mathrm{C} \pm 0.2$ for 24 hours. At the end, skin surface was cleaned by removing the excess formulation. Skin samples were cut into small pieces and accumulated APIs in the skin was extracted with the aid of a horizontal shaker in $5 \mathrm{ml}$ of methanol for 24 hours. The amount of MEL and OMC in samples were quantified with the HPLC method.

\subsection{Stability Studies of the MEL-OMC Microemulsion Formulation}

Stability studies were performed in stability cabinets at $40^{\circ} \mathrm{C}$ with $75 \%$ relative humidity (RH), $25^{\circ} \mathrm{C}$ with $60 \% \mathrm{RH}$ and at $4{ }^{\circ} \mathrm{C}$ for up to 3 months in terms of conductivity, droplet size, viscosity, $\mathrm{pH}$ and MEL and OMC concentration. The samples were analyzed by the newly developed HPLC.

\section{Results and Discussion}

\subsection{Preparation and Characterization of Microemulsions}

Pseudoternary phase diagram was constructed using IPM as oil, Tween 80 as surfactant and Transcutol P as co-surfactant. Figure 2 represents a large microemulsion area of 696.82 which was obtained with 2:1 surfactant and co-surfactant

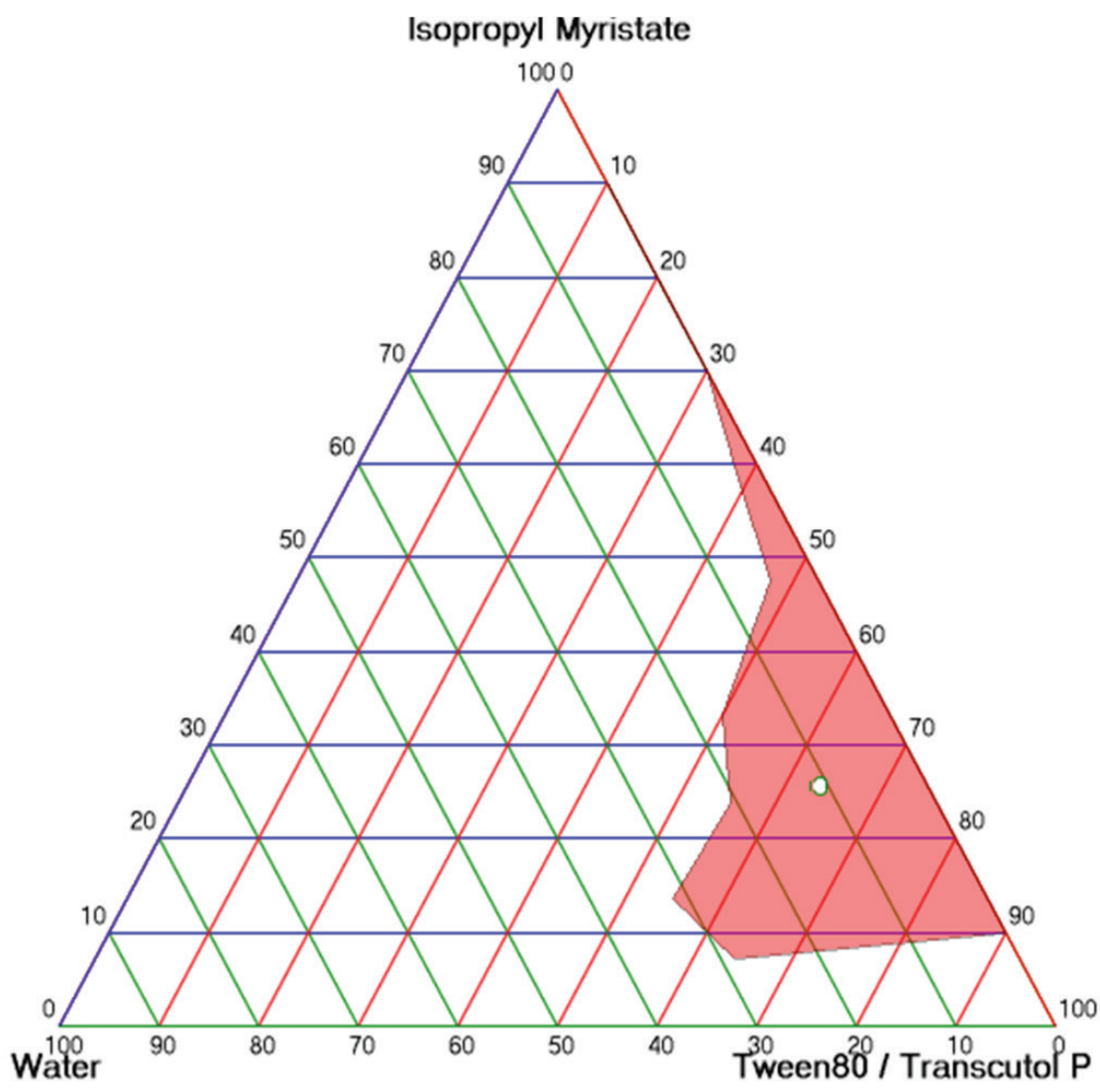

Figure 2. Pseudoternary phase diagram of the microemulsion formulation. 
mixture. The formulation consisting of $11 \%$ oil phase and $63 \%$ surfactant and co-surfactant mixture was selected from the microemulsion region and $1 \% \mathrm{MEL}$ and $5 \%$ OMC was added to the oil phase then the drug loaded formulation was characterized in terms of droplet size, polydispersity index, $\mathrm{pH}$ and viscosity. The drug loaded formulation has a droplet size of $193 \pm 1.41 \mathrm{~nm}$ with a polydispersity index of $0.471 \pm 0.032$. The acidity of the skin ranges from $\mathrm{pH} 4$ to 6 and $\mathrm{pH}$ levels ranging from 5-8 are acceptable for topical applications [13]. The $\mathrm{pH}$ of the formulation was found 6.35 \pm 0.02 indicating that the formulation is suitable for topical application. The formulation showed a low viscosity and measured as $360 \pm 0.57 \mathrm{cP}$ at $25 \pm 2^{\circ} \mathrm{C}$.

\subsection{Analytical Method Validation}

The summary of the validation parameters for the proposed method is presented in Table 2. Theoretical plate number is a measure of column efficiency. The efficiency of the method is expressed by the number of theoretical plates $(\mathrm{N})$, which assumed the value of 5490 and 111863 for MEL and OMC, respectively. These values are in agreement with FDA's recommended parameter of $\mathrm{N}>2000$ [14]. The accuracy of quantitation decreases with increase in peak tailing because of the difficulties encountered by the integrator in determining where/when the peak ends and hence the calculation of the area under the peak. The symmetry of the peak is established by symmetry factor. As peak symmetry moves away from values of 1 , integration, and hence precision, become less reliable (USP 37). Symmetry factors were calculated by The HP ChemStation and determined as 0.91 and 0.9 for MEL and OMC, respectively.

Table 2. Summary of validation parameters for the proposed method.

\begin{tabular}{lcc}
\hline \multicolumn{1}{c}{ Parameters } & MEL & OMC \\
\hline$\lambda \max (\mathrm{nm})$ & 222 & 306 \\
\hline Retention Time $(\mathrm{min})$ & 5.6 & 9.6 \\
\hline Theoretical plates & 5490 & 111863 \\
\hline Tailing factor & 0.91 & 0.9 \\
\hline Linearity range $(\mu \mathrm{g} / \mathrm{mL})$ & $0.5-60$ & $0.5-60$ \\
\hline Correlation coefficient $(\mathrm{r})$ & 0.9995 & 0.9991 \\
\hline LOD $(\mu \mathrm{g} / \mathrm{mL})$ & 0.132 & 0.049 \\
\hline LOQ $(\mu \mathrm{g} / \mathrm{mL})$ & 0.4 & 0.15 \\
\hline
\end{tabular}

The UV spectrum of MEL and OMC is presented in Figure 3. The UV spectrum of APIs in mobile phase was scanned in the region between 200 to $400 \mathrm{~nm}$. The $\lambda$ max values were determined at $222 \mathrm{~nm}$ and $306 \mathrm{~nm}$ for MEL and OMC, respectively. MEL showed a retention time at $5.6 \mathrm{~min}$ whereas OMC peak was seen at 9.6 min resulting that APIs were separated successfully.

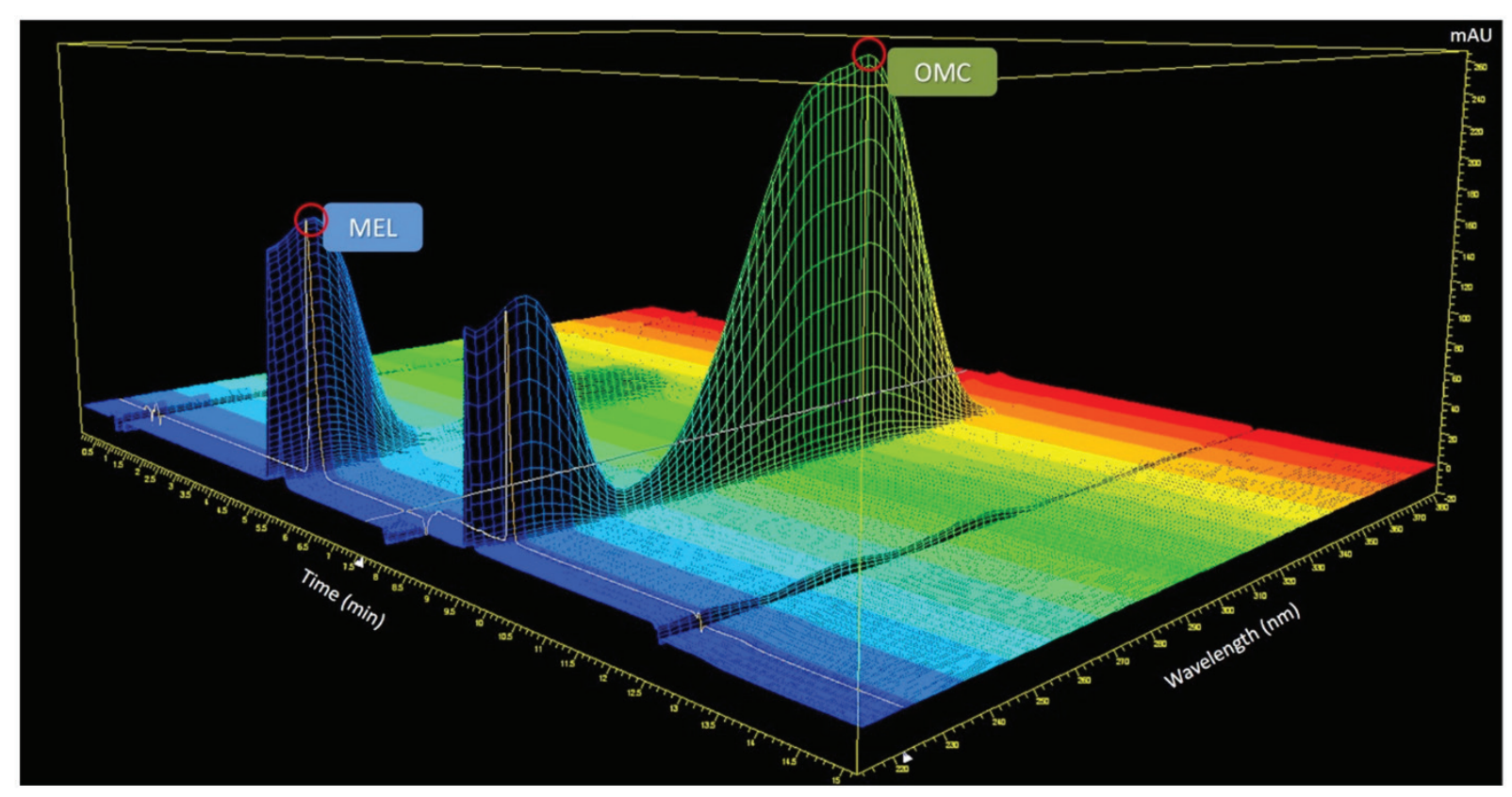

Figure 3. UV spectrum of melatonin and octyl methoxycinnamate. 
The specificity of the developed method was conducted in presence of dilution solution and placebo, which is the microemulsion formulation without APIs. A representative chromatogram of MEL and OMC standard solution is shown in Figure 4(A). It is shown in Figure 4(B) and Figure
4(C) that no peak due to placebo or dilution solution was detected at the retention time of MEL and OMC. Figure 4(D) represents the sample chromatogram. MEL and OMC were extracted from the microemulsion formulation by dissolving the formulation in ethanol.

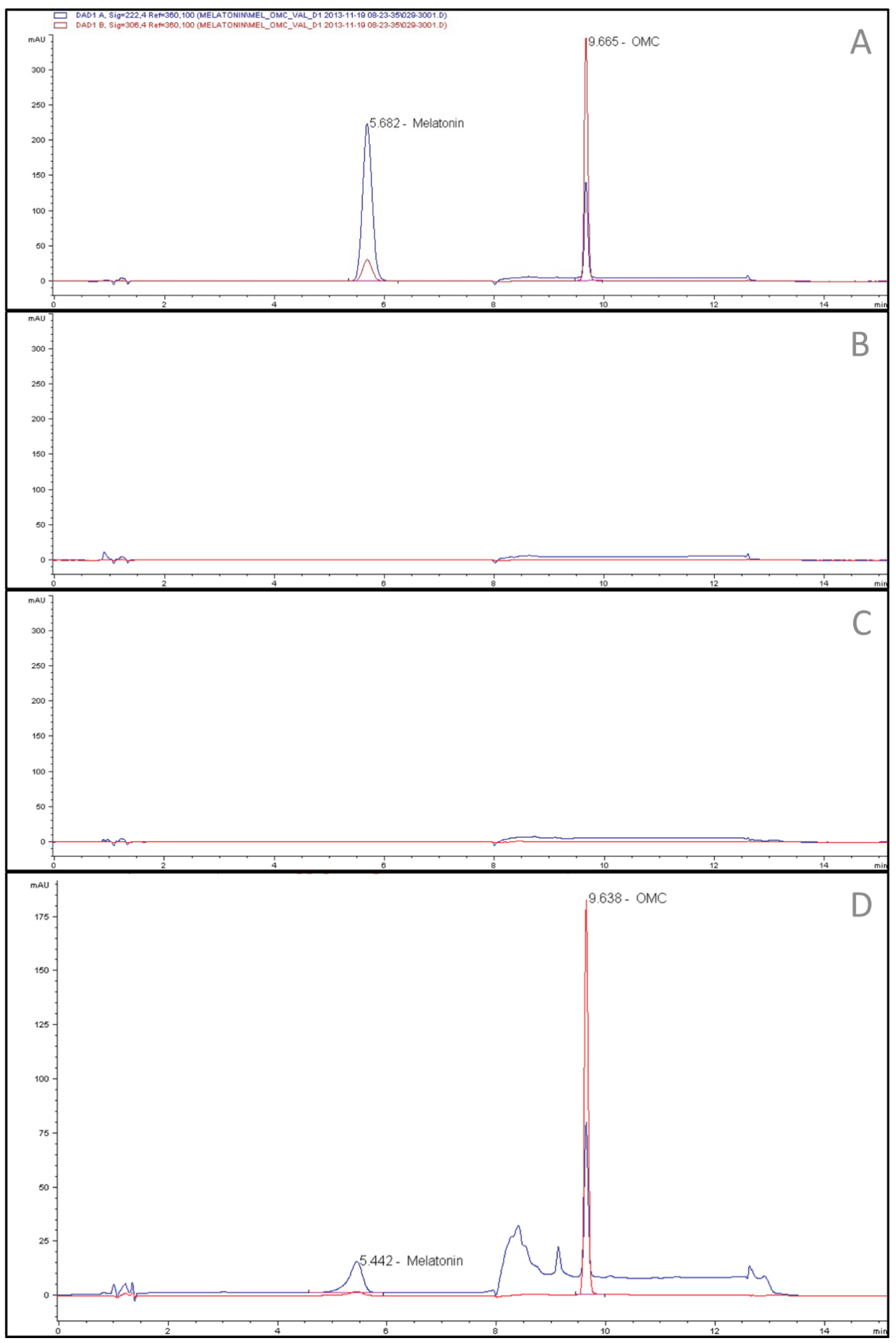

Figure 4. Chromotogram of (A) melatonin and octyl methoxycinnamate injection, (B) placebo, (C) dilution solution, and the sample chromatogram (D). 
The accuracy of the method was determined by recovery experiments which were evaluated in triplicate using three concentration levels. The percentage recovery data was obtained for MEL and OMC and presented in Table 3 and Table 4, respectively. The percentage recovery data were found to be accurate for both APIs.

Table 3. Recovery of MEL.

\begin{tabular}{|c|c|c|c|c|c|}
\hline$\mu \mathrm{g} / \mathrm{mL}$ Added & $\mu \mathrm{g} / \mathrm{mL}$ Found & \% Recovery & Mean & SD & RSD \% \\
\hline 40.102 & 40.522 & 101 & \multirow{3}{*}{101} & \multirow{3}{*}{0.074} & \multirow{3}{*}{0.073} \\
\hline 40.102 & 40.469 & 101 & & & \\
\hline 40.102 & 40.473 & 101 & & & \\
\hline 44.092 & 44.735 & 101 & \multirow{3}{*}{102} & \multirow{3}{*}{0.129} & \multirow{3}{*}{0.127} \\
\hline 44.092 & 44.816 & 102 & & & \\
\hline 44.092 & 44.845 & 102 & & & \\
\hline 42.142 & 42.825 & 102 & \multirow{3}{*}{102} & \multirow{3}{*}{0.034} & \multirow{3}{*}{0.034} \\
\hline 42.142 & 42.805 & 102 & & & \\
\hline 42.142 & 42.797 & 102 & & & \\
\hline 51.462 & 51.961 & 101 & \multirow{3}{*}{101} & \multirow{3}{*}{0.050} & \multirow{3}{*}{0.049} \\
\hline 51.462 & 52.001 & 101 & & & \\
\hline 51.462 & 52.009 & 101 & & & \\
\hline 51.763 & 52.015 & 100 & \multirow{3}{*}{100} & \multirow{3}{*}{2.535} & \multirow{3}{*}{2.533} \\
\hline 51.763 & 53.012 & 102 & & & \\
\hline 51.763 & 50.411 & 97 & & & \\
\hline 54.187 & 54.272 & 100 & \multirow{3}{*}{100} & \multirow{3}{*}{0.077} & \multirow{3}{*}{0.077} \\
\hline 54.187 & 54.329 & 100 & & & \\
\hline 54.187 & 54.353 & 100 & & & \\
\hline 63.346 & 63.460 & 100 & \multirow{3}{*}{100} & \multirow{3}{*}{0.030} & \multirow{3}{*}{0.030} \\
\hline 63.346 & 63.497 & 100 & & & \\
\hline 63.346 & 63.472 & 100 & & & \\
\hline 62.851 & 62.945 & 100 & \multirow{3}{*}{100} & \multirow{3}{*}{0.101} & \multirow{3}{*}{0.101} \\
\hline 62.851 & 62.953 & 100 & & & \\
\hline 62.851 & 63.059 & 100 & & & \\
\hline 67.267 & 67.329 & 100 & \multirow{3}{*}{100} & \multirow{3}{*}{0.046} & \multirow{3}{*}{0.046} \\
\hline 67.267 & 67.280 & 100 & & & \\
\hline 67.267 & 67.337 & 100 & & & \\
\hline
\end{tabular}

Table 4. Recovery of OMC.

\begin{tabular}{|c|c|c|c|c|c|}
\hline$\mu \mathrm{g} / \mathrm{mL}$ Added & $\mu \mathrm{g} / \mathrm{mL}$ Found & \% Recovery & Mean & SD & RSD \% \\
\hline 40.012 & 39.518 & 99 & \multirow{3}{*}{99} & \multirow{3}{*}{0.020} & \multirow{3}{*}{0.020} \\
\hline 40.012 & 39.518 & 99 & & & \\
\hline 40.012 & 39.532 & 99 & & & \\
\hline 42.998 & 43.043 & 100 & \multirow{3}{*}{100} & \multirow{3}{*}{0.115} & \multirow{3}{*}{0.114} \\
\hline 42.998 & 43.102 & 100 & & & \\
\hline 42.998 & 43.141 & 100 & & & \\
\hline 39.542 & 39.001 & 99 & \multirow{3}{*}{99} & \multirow{3}{*}{0.034} & \multirow{3}{*}{0.035} \\
\hline 39.542 & 38.974 & 99 & & & \\
\hline 39.542 & 38.989 & 99 & & & \\
\hline 50.227 & 50.217 & 100 & \multirow{3}{*}{100} & \multirow{3}{*}{0.034} & \multirow{3}{*}{0.034} \\
\hline 50.227 & 50.234 & 100 & & & \\
\hline 50.227 & 50.200 & 100 & & & \\
\hline 47.453 & 45.194 & 95 & \multirow{3}{*}{96} & \multirow{3}{*}{0.378} & \multirow{3}{*}{0.396} \\
\hline 47.453 & 45.383 & 96 & & & \\
\hline 47.453 & 45.553 & 96 & & & \\
\hline 50.009 & 50.954 & 102 & \multirow{3}{*}{102} & \multirow{3}{*}{0.067} & \multirow{3}{*}{0.066} \\
\hline 50.009 & 51.021 & 102 & & & \\
\hline 50.009 & 50.992 & 102 & & & \\
\hline 60.476 & 60.433 & 100 & \multirow{3}{*}{100} & \multirow{3}{*}{0.050} & \multirow{3}{*}{0.050} \\
\hline 60.476 & 60.469 & 100 & & & \\
\hline 60.476 & 60.493 & 100 & & & \\
\hline 61.267 & 62.132 & 101 & \multirow{3}{*}{101} & \multirow{3}{*}{0.055} & \multirow{3}{*}{0.054} \\
\hline 61.267 & 62.197 & 102 & & & \\
\hline 61.267 & 62.178 & 101 & & & \\
\hline 61.276 & 61.252 & 100 & \multirow{3}{*}{100} & \multirow{3}{*}{0.040} & \multirow{3}{*}{0.040} \\
\hline 61.276 & 61.264 & 100 & & & \\
\hline 61.276 & 61.299 & 100 & & & \\
\hline
\end{tabular}


The precision of method was verified by obtaining repeatability, intermediate precision and reproducibility parameters. The results of the reproducibility of the proposed method was shown in Table 5, which was determined by preparation of six different samples from the same stock solution at the same concentration of $50 \mu \mathrm{g} / \mathrm{ml}$. The results of repeatability and intermediate precision of the method was represented in Table 6 . Repeatability was checked by injecting six individual sample preparations of MEL and OMC at 50 $\mu \mathrm{g} / \mathrm{ml}$ concentration while the intermediate precision of the method was obtained by two analysts. Standard deviation (SD) and relative standard deviation (RSD) of the area for each API were calculated and evaluated.

Table 5. The results showing the reproducibility of the proposed method for precision study.

\begin{tabular}{ccc}
\hline \multirow{2}{*}{ Sample } & \multicolumn{2}{c}{ mAU } \\
\cline { 2 - 3 } & MEL & OMC \\
\hline 1 & 2001.6 & 992.8 \\
\hline 2 & 2002.8 & 996.6 \\
\hline 3 & 2004.1 & 1000.8 \\
\hline 4 & 2005.8 & 1005.3 \\
\hline 5 & 2007.8 & 1010.4 \\
\hline 6 & 2008.6 & 1015.9 \\
\hline Mean & 2005.12 & 1003.63 \\
\hline$S D$ & 2.78 & 8.65 \\
\hline$R S D \%$ & 0.14 & 0.86 \\
\hline
\end{tabular}

The linearity of the method was determined at six concentration levels $(60,40,20,10,5$ and $1 \mu \mathrm{g} / \mathrm{ml})$. The calibration curves were plotted between the responses of peak area versus concentration of analyte. The slope and intercept value for calibration curve was $y=41.787 \mathrm{x}-2.2207$ $\left(R^{2}=0.9995\right)$ for MEL and $y=24.662 x+0.5438\left(R^{2}=0.9991\right)$ for OMC. The results reveal that an excellent correlation exists between areas and concentration of APIs within the concentration range. Calibration curves are presented in Figure 5.

Detection limit and quantification limit of the method were determined by calculating the LOD and LOQ values using the equations given above. LOD values were found $0.132 \mu \mathrm{g} /$ $\mathrm{ml}$ and $0.049 \mu \mathrm{g} / \mathrm{ml}$ for MEL and OMC, respectively. LOQ values were determined as $0.4 \mu \mathrm{g} / \mathrm{ml}$ and $0.15 \mu \mathrm{g} / \mathrm{ml}$ for MEL and $\mathrm{OMC}$, respectively.

\subsection{Ex-vivo Permeation Study}

Ex-vivo permeation studies showed that neither MEL nor OMC permeated to the receptor phase of the Franz diffusion cells for up to 24 hours. At the end of the permeation study, the amounts of MEL and OMC remaining on the skin were quantified. The results showed that $3.504 \%$ MEL and 46.264 $\%$ OMC remained in the skin.

\subsection{Stability Studies of the Microemulsion Formulation}

The results of characterizations and 3 months stability of the proposed microemulsion formulation are presented in Table 7. Results are the mean of three replicates \pm SD. The studies

Table 6. The results showing the repeatability and intermediate precision of the proposed method.

\begin{tabular}{|c|c|c|c|c|}
\hline \multirow{3}{*}{ Sample } & \multicolumn{4}{|c|}{$\mathrm{mAU}$} \\
\hline & \multicolumn{2}{|c|}{ Analyst-1 } & \multicolumn{2}{|c|}{ Analyst-2 } \\
\hline & MEL & OMC & MEL & OMC \\
\hline 1 & 2018,60 & 1286,9 & 2099,7 & 1299,2 \\
\hline 2 & 2190,10 & 1322,8 & 2157,2 & 1339,5 \\
\hline 3 & 2081,70 & 1227,6 & 2105 & 1365,6 \\
\hline 4 & 2206,20 & 1336,4 & 2235,5 & 1397,3 \\
\hline 5 & 2236,20 & 1311,5 & 2221 & 1453,6 \\
\hline 6 & 2197,50 & 1266,5 & 2230,7 & 1328,8 \\
\hline Mean & 2155,05 & 1291,95 & 2174,85 & 1364 \\
\hline$S D$ & 77,71 & 36,80 & 62,9 & 55,10 \\
\hline$R S D \%$ & 3,61 & 2,85 & 2,9 & 4,04 \\
\hline
\end{tabular}



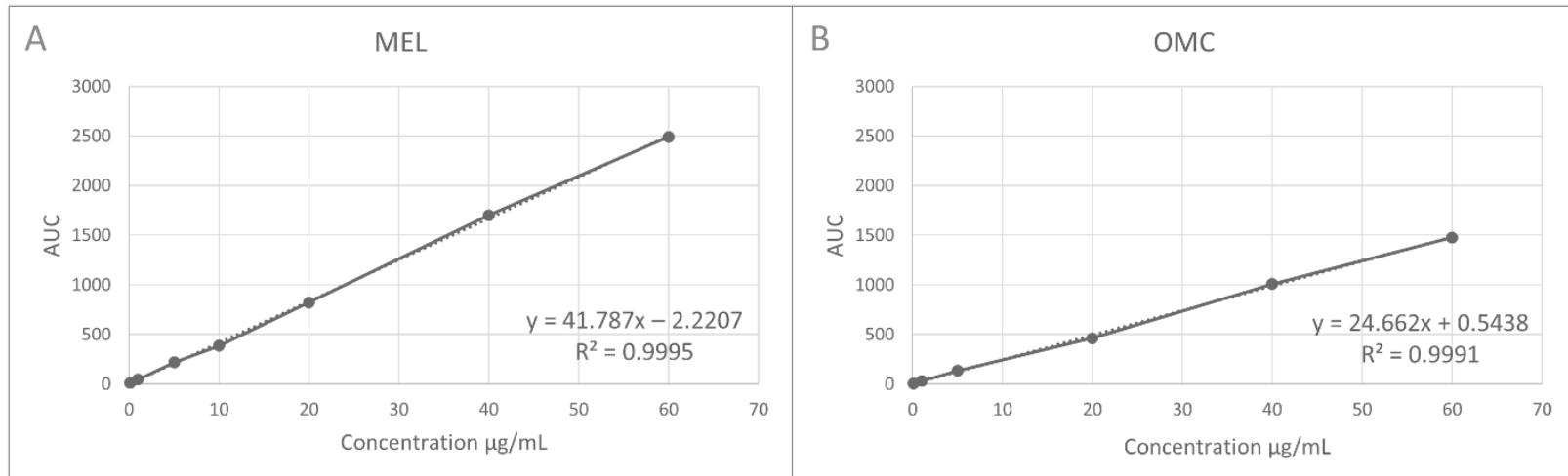

Figure 5. Calibration curves of melatonin and octyl methoxycinnamate.

Table 7. Characterizations and 3 months stability of the microemulsion formulation. Results are the mean of three replicates \pm SD.

\begin{tabular}{|c|c|c|c|c|c|c|c|}
\hline \multicolumn{2}{|c|}{ Time } & $\begin{array}{l}\text { Concentration } \\
\mathrm{mg} / \mathrm{ml}\end{array}$ & $\begin{array}{l}\text { Conductivity } \\
\mathrm{mS} / \mathrm{cm}\end{array}$ & $\begin{array}{c}\text { Droplet size } \\
\text { nm }\end{array}$ & PDI & $\begin{array}{l}\text { Viscosity } \\
\text { cP } 25^{\circ} \mathrm{C}\end{array}$ & $\mathrm{pH}$ \\
\hline & Tinitial & $\begin{array}{c}\text { MEL: } 9,754 \pm 0,358 \\
\text { OMC: } 50,188 \pm 0,804\end{array}$ & $0,032 \pm 0,005$ & $193,3 \pm 1,410$ & $0,471 \pm 0,032$ & $360 \pm 0.577$ & $6,35 \pm 0,025$ \\
\hline \multirow{3}{*}{ 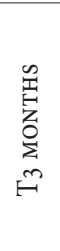 } & $4^{\circ} \mathrm{C}$ & $\begin{array}{c}9,842 \pm 0,850 \\
51,106 \pm 0,839\end{array}$ & $0,032 \pm 0,003$ & $262,333 \pm 3,955$ & $0,408 \pm 0,039$ & $363 \pm 0,862$ & $6,45 \pm 0,020$ \\
\hline & $25{ }^{\circ} \mathrm{C} 60 \% \mathrm{RH}$ & $\begin{array}{c}9,986 \pm 2,620 \\
51,889 \pm 2,371\end{array}$ & $0,032 \pm 0,003$ & $201,466 \pm 10,248$ & $0,664 \pm 0,073$ & $960 \pm 2,522$ & $6,55 \pm 0,043$ \\
\hline & $40^{\circ} \mathrm{C} 75 \% \mathrm{RH}$ & $\begin{array}{c}9,524 \pm 2,956 \\
50,024 \pm 2,438\end{array}$ & $0,033 \pm 0,001$ & $106,066 \pm 2,956$ & $0,829 \pm 0,071$ & $750 \pm 3,236$ & $6,43 \pm 0,036$ \\
\hline
\end{tabular}

revealed that the proposed formulation showed good stability at $25{ }^{\circ} \mathrm{C}$ with $60 \% \mathrm{RH}$ in terms of API concentrations, conductivity, droplet size and $\mathrm{pH}$. But the viscosity of the formulation was increased at the end of 3 months.

\section{Conclusion}

A simple, cost effective, specific, accurate and precise RP-HPLC method has been developed and validated for simultaneous estimation of MEL and OMC. To test the method a microemulsion formulation of MEL and OMC was also prepared and characterized. The determination coefficient for RP-HPLC method was found to be greater than 0.9990 . The linearity range was found in between 0.5 and $60 \mu \mathrm{g} / \mathrm{ml}$ for MEL and OMC. The developed method was successfully applied to prepared microemulsion formulation and the results were found with higher confidence. The method was validated for accuracy, precision, specificity, and linearity according to guidelines. Also the method was successfully used for determination API concentration in ex-vivo permeation and stability studies of the proposed microemulsion formulation composed of MEL and OMC. In conclusion, this method can be used for determination of MEL and OMC in pharmaceutical formulations.

\section{Conflicts of interest}

The authors reveal no conflict of interest in this manuscript.

\section{Acknowledgments}

This study was supported by Ege University, Scientific Research Projects No: 13-ECZ-003. We also thank to Dr. Mehmet Ali Ege from Ege University Faculty of Pharmacy and Department of Pharmaceutical Technology for giving permission to use pseudo-ternary phase diagram program.

\section{References}

1. Slominski A, Fischer TW, Zmijewski MA, Wortsman J, Semak I, Zbytek B, Slominski RM, Tobin DJ. On the role of melatonin in skin physiology and pathology. Endocr 2005; 27: 137-48.

2. Slominski AT, Kleszczyński K, Semak I, Semak I, Janjetovic Z, Zmijewski MA, Kim TK, Slominski RM, Reiter RJ, Fischer TW. local melatoninergic system as the protector of skin integrity. Int J Mol Sci 2014; 15: 17705-32. 
3. Sierra AF, Ramírez MLG, Campmany ACC, Martínez AR, Naveros BC. In vivo and in vitro evaluation of the use of a newly developed melatonin loaded emulsion combined with UV filters as a protective agent against skin irradiation. J Dermatol Sci 2013; 69: 202-14.

4. Marto J, Ascenso A, Gonçalves LM, Gouveia LF, Manteigas P, Pinto P, Oliveira E, Almeida AJ, Ribeiro HM. Melatoninbased pickering emulsion for skin's photoprotection. Drug Deliv 2016; 23: 1594-607.

5. Wang SQ, Lim HW. Current status of the sunscreen regulation in the United States: 2011 Food and Drug Administration's final rule on labeling and effectiveness testing. J Am Acad Dermatol 2011; 65: 863-9.

6. Heuschkel S, Goebel A, Neubert R.H.H. Microemulsionsmodern colloidal carrier for dermal and transdermal drug delivery. J Pharm Sci 2008; 97: 603-31.

7. Lopes LB. Overcoming the cutaneous barrier with microemulsions. Pharmaceutics 2014; 6: 52-77.

8. Carlotti ME, Gallarate M, Rossatto V. O/W microemulsion as a vehicle for sunscreens. J Cosmet Sci 2003; 54: 451-62.
9. Lin J, Zhang C, Gao Y, Zhao X, Li X. A validated HPLC method for determining melatonin in capsule dosage form. Spatula DD 2012; 2: 147-51.

10. Kedor-Hackmann ERM., De Lourdes Pérez González ML, Singh AK, Santoro MIRM. Validation of a HPLC method for simultaneous determination of five sunscreens in lotion preparation. Int J Cosmet Sci 2006; 28: 219-24.

11. Andrisano V, Bertucci C, Battaglia A, Cavrini V. Photostability of drugs: Photodegradation of melatonin and its determination in commercial formulations. J Pharm Biomed Anal 2000; 23: 15-23.

12. ICH (Q2 (R1); Validation of Analytical Procedures: Text and methodology. International Conference on Harmonization, Geneva. 2005.

13. Songkro S, Lo NL, Tanmanee N, Maneenuan D, Boonme P. In vitro release, skin permeation and retention of benzophenone-3 from microemulsions (o/w and w/o). J Drug Deliv Sci Technol 2014; 24: 703-11.

14. FDA, Reviewer Guidance-Validation of chromatographic methods. Rockville, United States of America. 1994. 